\title{
Working Mothers Satisfaction: The Influence of Time Demands and Time- Based Conflict
}

\section{Berger L*}

Faculty of Psychology, Skidmore College, USA

\begin{abstract}
A comprehensive model of work-family conflict and family-work conflict for working mothers was examined and tested. Specifically, the hypothesis that time-based work-family conflict and time-based family-work conflict was expected to fully mediate the relations between work hours, work demands, and family demands on work and family satisfaction. The 677 working mother participants were well-educated and married, a limitation and consideration. Results demonstrated support for the hypothesized fully mediating model. Working mothers with greater demands and higher work hours had higher work-family conflict, and this in turn was related to lower work satisfaction. Working mothers with greater demands experienced significantly higher family-to-work conflict and subsequently had lower family satisfaction. Implications, strengths, limitations and directions for future research are addressed.
\end{abstract}

Keywords: Working mothers; Work-family conflict; Work satisfaction; Family satisfaction; Time demand

\section{Introduction}

Employed women with children at home experience more stressors than do those without children, as they have to balance two important roles: mother and employee [1]. For the purpose of this paper, the terms employed mothers and working mothers will be used interchangeably. Broadly defined, a working mother is any woman who is employed, receives monetary compensation for her employment, and is legally responsible for at least one child [2]. To put this in context, recent data demonstrates that approximately 25.2 million mothers are employed in the United States [3]. The subject of working mothers has become a focus of the vocational literature due to the increase of employed mothers over the past decade.

One topic regarding employed mothers that is frequently researched, in conjunction with satisfaction, is the incompatibility of home and work responsibilities. The clash between responsibilities can lead mothers to experience higher levels of conflict both at home as a mother and at work as an employee; this incompatibility between work and family is defined by the theoretical model of work-family conflict [4]. The theory of work-family conflict (WFC) and family-work conflict (FWC) posits that conflict will arise and increase as a direct result of the incompatibility between a person's role requirements, for example, as a mother and an employee. Both roles (mother and employee) are demanding, making it difficult to achieve a satisfied balance between the two.

Furthermore, these conflicts can be particularly relevant as mothers attempt to balance their roles in the allotted time they have to dedicate to work and family. These time conflicting roles likely have negative consequences and are recognized as significant predictors of a mother's satisfaction with her family and her job [5]. In fact, research indicates that employed mothers experience high stress when balancing family and work demands, specifically perceived as time pressures [6]. When mothers perceive their demands at home and at work as imbalanced, they encounter conflict between these two salient roles, decreasing their satisfaction at home and at work $[7,8]$.

According to Higgins, et al. [9], one of the most important time pressures that influence the working mother's family and work satisfaction as well as the ability to balance work and home demands is the physical number of work hours per week. Several constructs appear to be involved when evaluating the interplay of work and family by Bryon [10]. The literature, however, is beset with methodological and conceptual flaws and conflicting findings, making theoretical conclusions a cautious fete. Although the WFC literature has advanced and appears substantial, it is nevertheless at times ambiguous. In short, there are five salient problems in the literature: (a) the lack of research on U.S. working mothers [10] (b) the dichotomization of work hours as part-time versus full-time [11], (c) the fragmentation and separate study of WFC and FWC [12], (d) the exclusion of family satisfaction as an outcome of work-related antecedents [13] and (e) the ambiguity of the WFC theoretical model and the need to test specific sources of conflict.

The purpose of the current study is to attempt to address some of the deficiencies in the literature and to clarify and expand the work family research and broader theory. Specifically, the intent is to test a mediated model of antecedents (demands and work hours), conflict, and satisfaction that specifically encompasses both work and family components throughout-WFC and FWC mediate the relations between work and family antecedents and work and family satisfaction. This will be accomplished in part by testing empirically the mediation components of Greenhaus and Beutell's model of WFC/FWC.

\section{Understanding the Constructs}

\section{Model of work-family conflict}

WFC and FWC are widely defined as the "form of inter-role conflict in which the role pressures from the work and family domains are mutually incompatible in some respect. That is, participation in the work role is made more difficult by virtue of participation in the

*Corresponding author: Berger L PhD, Visting Assistant Professor, Faculty of Psychology, Skidmore College, USA, Tel: 518-527-6559; E-mail: Lberger@skidmore.edu

Received February 25, 2018; Accepted March 20, 2018; Published March 27 2018

Citation: Berger L (2018) Working Mothers Satisfaction: The Influence of Time Demands and Time-Based Conflict. J Ment Disord Treat 4: 158. doi:10.4172/2471271X.1000158

Copyright: (C) 2018 Berger L. This is an open-access article distributed under the terms of the Creative Commons Attribution License, which permits unrestricted use, distribution, and reproduction in any medium, provided the original author and source are credited. 
family role" [5]. WFC indicates that work conflict influences a mother's experience with her family whereas FWC indicates that family conflict influences a mother's experience at work. Dependent upon which comes first (i.e., work or family) is where the conflict originates. WFC and FWC are theorized as being distinct forms of conflict yet similar as they both involve the interaction between the domains of work and family [14]. For the purpose of this study, time-based WFC/FWC will only be addressed (there are three types of WFC/FWC: time, strain, and behavior), as the WFC model posits that time demands (work hours, family demands, and job demands) are antecedents of time-based conflict [5].

Time-based WFC/FWC is defined as a specific type of conflict where "multiple roles may compete for a person's time. Time spent on activities within one role generally cannot be devoted to activities within another role". An example is a working mother who is asked to work late by her boss when she has a prior commitment of picking up her children at daycare. This mother now experiences pressure from her role as an employee as well as the strain on her role as a mother because she is unable to tend to her children's needs. In this way, the physical time demands of work responsibilities contribute to stress [15]. In comparison, time-based FWC can be seen in a mother's needing to get her child ready in the morning and dropped off to childcare, causing her to be late to work and subject to negative consequences, decreasing her satisfaction with work and family.

When mothers have high strain and conflict, they experience low levels of satisfaction as they have multiple roles that result in the depletion of her physical and mental resources [16]. Thus, those with too many demands may feel a sense of overload and role strain. If the demands of the roles become overwhelming, high levels of conflict both at work and at home can result [17]. These demands lead to less time to dedicate to either role.

The most relevant theory to the study of time-based WFC/FWC is the scarcity hypothesis $[5,7,17,18]$. The scarcity hypothesis states that "individuals have limited time and energy, and adding extra roles and responsibilities necessarily creates tensions between competing demands and a sense of overload and inter-role conflicts" [19]. Specifically, the roles of mother and employee are both demanding, which leads mothers to negotiate their time and responsibilities, resulting in conflict and lower levels of satisfaction within these role domains. A mother will experience lower levels of satisfaction, when the time between roles cannot be negotiated [20]. The consequence is that mothers with multiple roles may feel depleted and have lower levels of work and family satisfaction [21]. In return, it is not only the conflict between work and family, but also what has caused the conflict and subsequently what the conflict then produces, considered a domino effect.

\section{Work and family demands}

Work demands and family demands can be defined as "a global perception of the level and intensity of responsibility within the work family domain" [22]. Role overload, in the form of demands, occurs when a woman attempts to balance being an employee and a mother. Balancing these demands leads to lower levels of satisfaction because the mother feels "spread too thin" between work and family commitments. Ultimately, the higher the demands, the higher the feeling of overload and the greater the decrease in work and family satisfaction. Work demands related to time include the time pressures of work hours, high workloads, unfavorable work schedules, high expectations from managers, and short deadlines [22]. Brough, et al. [23] stated, "If a person has to work long hours and/or experiences considerable job demands, these in turn will reduce the capacity to devote time and energy to their family life". The additional strains on a mother's role as an employee leads to higher conflicts and lower levels of work and family satisfaction, consequently increasing susceptibility to depression and burnout [24].

Family demands also influence a mother's balancing of work and family. Family demands can be defined as "a global perception of the level and intensity of responsibility within the family domain". The more a mother has to negotiate these demands between work and family, the higher the WFC/FWC and the lower the work and family satisfaction.

\section{Satisfaction}

Being that both work and family influence a mother's satisfaction, the most relevant aspects of satisfaction are work satisfaction and family satisfaction. Furthermore, family variables have explained variance in work satisfaction and work variables have been shown to explain variance in family satisfaction.

\section{Work satisfaction}

Employed mothers tend to report lower levels of job satisfaction than women without children [25]. In fact, job satisfaction is a common type of domain satisfaction of employed mothers that has been measured. WFC accounts for $40 \%$ of the variance in job satisfaction [26]. A meta-analysis of FWC/WFC and job satisfaction found a significant negative relation between conflict and job satisfaction [27]. Kossek et al. [27] found that FWC also predicted work dissatisfaction, which is expected based on the notion of spillover (defined as work influencing family and family influencing work), as experiences at work influence satisfaction at home [28]. Based on the Kossek et al. [27] meta-analysis, and a follow-up meta-analysis by Shockey and Singla [6] it is clear that not only do WFC and FWC predict work satisfaction, but also act as mediators of time commitments and work satisfaction. The literature demonstrates that job characteristics such as hours worked and job demands are negatively related to an employed mothers work satisfaction [25].

\section{Family satisfaction}

Similar to job satisfaction, family satisfaction is defined by both affective and cognitive perceptions (emotions and thoughts) of an individual's experiences at home [29]. One approach to understanding the construct of family satisfaction is the circumplex model [30] which includes two dimensions: family cohesion and family flexibility. When a mother feels stretched between work and family, her perception of family cohesion and flexibility is influenced. In turn, this causes her to feel time deficits with her family and consequently can influence her level of family satisfaction.

Conflict, originating either at home or at work, has been shown to affect significantly a mother's family satisfaction, accounting for $38 \%$ of the variance. Significant inverse relationships have been shown between FWC and family satisfaction as well as WFC and family satisfaction. Family satisfaction has been studied although not as commonly as job satisfaction. Allen et al. [12] recognized the importance of future research to capture the "non-work" satisfaction, to fully comprehend cross-domain theoretical implications.

\section{Issues with previous research}

Notably, the majority of the literature regarding employed mothers, specifically employed mothers satisfaction (e.g., life, family, marital, 
job), has been conducted outside of the U.S. [31]. The theoretical underpinnings of WFC argue that it is not one domain that causes the conflict, but rather the combination of both work and family [5]. However, it is not uncommon to encounter literature that appears fragmented and compartmentalized [32]. Frequently, authors will measure WFC rather than capture the entirety of the theory. Fourth, some authors have suggested the need to include work and family satisfaction conjointly, rather than evaluate just one type of satisfaction. This cross-over is described as "cross-domain relations" which is formally defined as, "the extent to which factors in the work domain are related to satisfaction with family life and the extent to which factors in the family domain are related to satisfaction with work life".

In fact, Madsen and Hammond [32] acknowledged that the WFC literature has reached a complex point - widespread and lacks cohesion. Both continuity and consistency required to advance the WFC literature is sparse, a major problem for further theory development. Lastly, and related to the problem of conceptual inconsistency, the WFC literature uses several different terms to address similar concepts (e.g., conflict, interference, strain, spill-over) [32]. This contributes to the lack of conceptual clarity, specifically that several distinct constructs are equivocated (e.g., WFC and work-family interference). Similarly, the majority of the WFC literature addresses the constructs of WFC/ FWC as a whole (integrating all three dimensions- time, strain, and behavioral conflicts); thus, research on the antecedents and effects of each individual dimension of conflict is needed to promote conceptual clarification and a better understanding of the theory [33,34]. As recommended by Allen et al. [12], researchers need to look at the specific dimensions of WFC and how they specifically contribute to satisfaction. Likewise, researchers have highlighted the need to conduct research on a dimension specific conflict because different types of conflicts have distinctive effects on well-being. Accordingly, one particular antecedent of time-based conflict is work hours [8].

\section{Hypotheses}

The current study seeks to test empirically an integrative model wherein WFC/FWC mediate the relationships between work and family antecedents and work and family satisfaction. In addition, it seeks to advance the literature in the following several ways: (a) By operationalizing work hours as a continuous variable to preserve the construct of work hours, reflective of the definition within the U.S.; (b) By testing two specific time-related forms of WFC/FWC; (c) By taking into account conjointly work and family constructs. Thus, the intent of this study is to test a mediated model that encompasses both work and family from predictors to outcomes based on empirical recommendations.

First, to be consistent with previous findings $[35,36]$ and based on Greenhaus and Beutell's model of WFC, it is expected that TBWFC and TBFWC will fully explain the relations between work demands, family demands, work hours and work and family satisfaction. For instance, those mothers with longer work hours, higher family and home demands, will have higher conflict because they have less time to dedicate to work and family and consequently, lower satisfaction at home and at work. The fully mediated model will evidence that the antecedents of demands at work and home do not directly predict a working mother's level of satisfaction.

A fully mediated model is hypothesized $\left(\mathrm{H}_{1}\right)$ to best fit the data compared to a partial mediated or non-mediated model. As recommended by Mac Callum et al. [37], competing models will be tested in order to determine which is the best fitting model, ultimately hypothesizing that the fully mediated model will best capture the data. In addition, secondary pathway hypotheses, also considered in the overall model, are expected to include a significant positive relation between work hours and WFC $\left(\mathrm{H}_{\mathrm{A}}\right)$, work hours and FWC $\left(\mathrm{H}_{\mathrm{B}}\right)$ work demands and WFC $\left(\mathrm{H}_{\mathrm{C}}\right)$, work demands and FWC $\left(\mathrm{H}_{\mathrm{D}}\right)$, family demands and WFC $\left(\mathrm{H}_{\mathrm{E}}\right)$, family demands and FWC $\left(\mathrm{H}_{\mathrm{F}}\right)$. Lastly, it is expected that there will be significant negative relations between WFC and work satisfaction $\left(\mathrm{H}_{\mathrm{G}}\right)$, WFC and family satisfaction $\left(\mathrm{H}_{\mathrm{H}}\right)$, FWC and work satisfaction $\left(\mathrm{H}_{\mathrm{T}}\right)$, and FWC and family satisfaction $\left(\mathrm{H}_{\mathrm{T}}\right)$. If the mediated effects are found to be fully mediated variables we can conclude satisfaction is best understood via specific forms of conflict (time-based) and that cross-domain antecedent demands indirectly explain why mothers experience varying levels of satisfaction, ultimately wanting to reduce conflict in order to increase satisfaction.

\section{Method}

\section{Participants}

A total of 753 employed mothers completed materials for the study. Due to the inclusion/exclusion criteria or missing data, 677 employed mothers qualified and were included in the final sample (14 participants were excluded based on identifying being a single mother without cohabitating). Mothers who were citizens in the U.S., of any race and socio-economic status, currently employed and monetarily paid, qualified for this study. In addition, working mothers who met the criteria also had at least one child under the age of 18 (biological or adopted) under the mother's legal and physical custody and physically living in the same home.

The mothers ranged from 23 to 60 years old $(M=36.49, S D=6.84$ $73.6 \%$ were 40 years of age or younger), with $91.7 \%$ of the women identifying as Caucasian, 2.1\% Hispanic/Latina, 1.9\% Asian/Asian American, 1.3\% Biracial, 1.0\% African American, and 1.8\% identifying as "other". In regard to sexual orientation, $96.9 \%$ of the sample identified as Heterosexual, with $0.7 \%$ identifying as Homosexual and $2.1 \%$ identifying as Bisexual. Ninety-six percent of the women were married, $3.4 \%$ as cohabitating. The participants reported that their partner's worked on average 43.70 hours per week ( $M d n=40.00$, $\mathrm{SD}=12.681$ ). The majority of the women held either a Bachelor's (35.9\%) or Master's (38.0\%) Degree, with $8.4 \%$ having a GED, $8.3 \%$ having an Associate's Degree, 8.8\% holding a Medical, Juris Doctorate, or other Doctoral Degree (M.D., Ph.D., Psy.D., J.D., Pharm.D). The participants individual income varied from $\$ 1,000.00$ to $\$ 800,000.00$ $(M=\$ 63,052.78, M d n=\$ 56,000.00, S D=\$ 55,730.44)$. Similarly, their gross total household income (pre-tax) ranged from $\$ 5,000.00$ to $\$ 800,000.00(\mathrm{M}=\$ 131,994.88, \mathrm{Mdn}=\$ 118,500.00, \mathrm{SD}=\$ 80,304.49)$.

When looking at specific characteristics of the employed mothers, $40 \%$ of the mothers were between the ages of 27-30 when they had their first child $(M=29.56, M d n=29.0, S D=4.46)$. The participant's job titles varied across over eighty different professions ranging from Director/ Manager (27.2\%), Teacher (13.0\%), Secretary/Administrative Assistant (6.8\%), Counselor/Social Worker (5.9\%), Financial Planner/Analyst (4.4\%), Professor or Dean (4.0\%), Real Estate Agent (3.6\%), Attorney (2.9\%), Nurse (2.8\%), and Self-Employed (2.1\%). In fact, $89.1 \%$ of the women reported working one job, with $9.5 \%$ working two jobs and $1.0 \%$ working three jobs. Finally, $40.1 \%$ of the sample had one child, $44.9 \%$ had two children, $12.3 \%$ had three children, and $2.6 \%$ had four or more children $(\mathrm{M}=1.78, \mathrm{Mdn}=2.0, \mathrm{SD}=0.79)$. The average age of the children reported was 5.57 years old $(\mathrm{Mdn}=3.5, \mathrm{SD}=5.03)$. 


\section{Measures}

\section{Work and family demands}

Work and family demands were measured by the Perceived Work and Family Demands Scale (PWFDS) These perceived demands are considered overall time demands that cause conflict at work or at home. The PWD consists of five items and the PFD consists of four items rated on a 5-point Likert scale, with $1=$ strongly disagree and $5=$ strongly agree. Scores are obtained by summation of total responses, ranging from 5 to 25 for the PWD and 4 to 20 for PFD. Higher scores are indicative of higher demands.

A confirmatory factor analysis (CFA) with three separate samples determined a two-factor model of perceived work demands (PWD) and perceived family demands (PFD) provided the most adequate fit. Internal consistency from the original sample used to create the PWD scale was Cronbach's $\alpha=0.83$. Discriminant validity for PWD has been demonstrated by comparing PWD to work role overload $(\mathrm{r}=0.60)$, work role ambiguity $(\mathrm{r}=0.49)$, and work role conflict measures $(\mathrm{r}=0.57)$ PWD demonstrated predictive validity for work-family conflict using the MultiDimensional Work-Family Conflict Scale $(\mathrm{r}=0.37)$. For the current study, internal consistency yielded an alpha of 0.85 .

Internal consistency for PFD was found to be $\alpha=0.88$ in a sample of 187 U.S. men and women. The PFD subscale has demonstrated predictive validity for FWC ( $\mathrm{r}=0.43$ and discriminant validity from Family Role-Conflict ( $\mathrm{r}=0.50)$ and Family Role Ambiguity ( $\mathrm{r}=0.49)$. The current sample yielded internal consistency at $\alpha=0.72$.

\section{Work hours}

Work hours are defined as the average number of paid hours worked per week-a continuous variable. Work hours were measured by one item: "Please indicate the average number of hours you work per week."

\section{Time-based work-family conflict and time-based family- work conflict}

The Multi-Dimensional Work-Family Conflict Scale (MWFCS) [38] is an 18-item measure that includes six dimensions of work-family conflict. This measure was initially developed in response to the many inconsistent and unreliable work-family conflict measures [27]. Only two subscales, Time-Based Work Interference with Family (WIF) and Time-Based Family Interference with Work (FIW) subscales, were used to measure the mediating variables. The two time-based MWFCS subscales include three items each that are rated on a 5-point Likert scale, with $1=$ strongly disagree and $5=$ strongly agree. Scoring occurs by taking the average of each subscale, ranging from 0 to 5 . There are no reverse scored items and higher scores indicate higher conflict.

A CFA of 228 MBA students supported a six-factor WFC hypothesized model. The MWFCS demonstrates a high level of internal consistency (Cronbach's $\alpha=0.79$ to 0.89 ) Carlson also found high internal consistency with a sample of 225 full-time employed men and women, with Cronbach's alphas ranging from 0.76 to 0.89 . Hughes and Parkes [35] also used the MWFCS to test WFC and found an alpha level based on a sample of working mothers to be $\alpha=0.89$. More specifically, the time-based WIF yielded $\alpha=0.87$ and, for time-based FIW, $\alpha=0.79$ based on an international sample of 1553 working men and women [39]. The MWFCS also demonstrated good predictive validity of life stress ( $\mathrm{r}=0.29$ for FWC and $\mathrm{r}=0.43$ for WFC) and concurrent validity such as FRC and TBFWC $\mathrm{r}=0.25$ and work involvement with WFC, $r=0.37$ [36]. For the current sample, time-based WIF demonstrated similar internal consistency with $\alpha=0.78$ and time-based FIW yielding $\alpha=0.80[40]$.

\section{Work satisfaction}

The abridged Job in General Scale [41] was used to measure the construct of work satisfaction. The aJIG was created in response to shortening the longer 18-item version of the Job in General Scale. (JIG) [40]. Both the JIG and aJIG are recognized as global measures of work satisfaction. Russel et al. [41] developed the aJIG via scale reduction and determined that 8 items was adequate as opposed to the original 18 in the JIG. Responses to the 8 items includes yes, no, or a (?) which indicates, "I do not know or I cannot decide". Sample items include, "Good," and "Undesirable". Responses range from Yes (Y) indicating 3 to No (N) being 0 and "?". Overall, higher scores indicate higher of job satisfaction, ranging from 0 to 24 .

The aJIG has high internal consistency ranging from Cronbach's $\alpha=0.85$ to $\alpha=0.87$ [41]. The aJIG demonstrated convergent validity with the JDI as well as the Organizational Commitment Questionnaire. A Cronbach's alpha for an additional study was 0.92 where the sample consisted of 220 employees. The aJIG appears to yield psychometrically sound scores of work satisfaction. For the current study, internal consistency yielded a Cronbach's alpha of 0.80 .

\section{Family satisfaction}

Family satisfaction was measured using the Family Satisfaction Scale (FSS). The scale captures aspects of family cohesion and family adaptability. The FSS has 10 items that are rated on a 5-point Likert scale, with $1=$ very dissatisfied to $5=$ extremely satisfied (five items per subscale). There total score represents the individual's overall satisfaction with family and ranges from 10-50, with 45-50 indicating high satisfaction and 10-25 indicating very low satisfaction. The 10item measure was tested on 2,465 individuals (married couples, college students, and adolescents) and demonstrated internal consistency, $\alpha=0.92$. For the current study, the FSS yielded an internal consistency of $\alpha=0.93$.

\section{Procedure}

Participants received the survey either via Internet (Online blogs and discussion groups for working mothers). Participants received an e-mail or blog post with a cover letter that included general information about the study and a link to the online website (Psychdata.com) where the study was provided. The instruments were distributed to participants through PsychData, a password protected online survey system, and took 15 minutes to complete. Being that a snowball sampling method was employed, response rates cannot be estimated. The first page of the study included the informed consent. Prior to indicating consent, a cover letter informed participants that this study "seeks to better understand the experiences of working mothers. Participants were solicited through working mother support websites, and e-mail listservs (working mother listservs). A drawing for three \$250.00 Amazon gift cards was randomly raffled at the conclusion of the study.

\section{Results}

\section{Norm comparison testing}

Norm comparison testing assessed for differences between the current sample and the samples used to develop the measures used in this study. Compared with Hughes and Parkes [35] the norm sample averaged fewer work hours $(\mathrm{M}=35.08, \mathrm{SD}=8.52)$, whereas the current study averaged 38.36 hours per week $(S D=9.98)$. The t test 
revealed significant differences, $t(675)=8.551, \quad \eta^{2}=0.049, \rho^{2}=0.048$, $\mathrm{p}=0.001$, therefore, the current sample of working mothers worked significantly more hours than the norm sample. For PWD, the norm sample mean was 3.79 , and in the current study $\mathrm{M}=3.60, \mathrm{SD}=0.78$. A $\mathrm{t}$ test, $\mathrm{t}(675)=-6.338, \eta^{2}=0.056, \hat{\rho}^{2}=0.055, \mathrm{p}<0.0001$, indicated that the current sample reported a significantly lower level of PWD than the normed sample. For PFD, the norm sample had a mean of 3.70, and the current study $\mathrm{M}=3.72, \mathrm{SD}=0.70$. A t test on the difference between the means, $\mathrm{t}(675)=0.743, \eta^{2}=0.000, \hat{\rho}^{2}=0.000, \mathrm{p}=0.536$, found no significant difference of PFD between the two samples. The norm study mean for TBWFC was $\mathrm{M}=2.82$ and the current study $\mathrm{M}=2.80, \mathrm{SD}=0.98$, with $\mathrm{t}(675)=-0.531, \eta^{2}=0.000, \rho^{2}=0.000, p=0.602$, indicating no significant difference between the two samples. However, for TBFWC, norm $\mathrm{M}=2.01$, and the current study $\mathrm{M}=2.66, \mathrm{SD}=0.94$, found $\mathrm{t}(675)=17.992$, $\eta^{2}=0.323, \rho^{2}=0.322, p<0.001$, demonstrating that the present sample of working mothers specifically reported much higher TBFWC. These results suggest that the current sample experienced higher levels of conflict transferred from home to work.

Norm comparison testing between the norm sample $(\mathrm{M}=17.52)$ and the current study for the aJIG (work satisfaction) demonstrated that the current sample reported a significantly higher level of work satisfaction than the normed sample used to develop the aJIG $(M=19.37, \mathrm{SD}=5.42)$. A $t$ test found $t(675)=8.881, \eta^{2}=0.104, \rho^{2}=0.103, p<0.0001$. On the contrary, norm comparison testing between the norm sample for the FSS $(M=37.50)$ and the current study $(M=35.00, S D=7.24)$, found $\mathrm{t}(675)=-8.980, \eta^{2}=0.107, \rho^{2}=0.105, \mathrm{p}<0.0001$ exhibited that the present sample of working mothers reported lower levels of family satisfaction than the normed sample.

\section{Descriptive results}

Of the 677 employed mothers, $14.6 \%$ defined their employment as part-time whereas $81.4 \%$ identified their employment as fulltime. The average hours of work per week ranged from 3 hours to 70 hours $(M=38.36, M d n=40.0, S D=9.98)$. Notably, $41.4 \%$ of the women reported reducing their work hours after having a child. There was a significant difference between self-reported part-time versus full-time, $\mathrm{t}(675)=118.09, \mathrm{p}=0.001, \rho^{2}=0.976$. The participants were asked, "How do you think being a mother affects your work performance?" and "How do you think that being an employee affects your performance as a mother?" Responses were based on a scale of 1 to 7 (1=totally does not affect and $7=$ totally affects). For how mothering impacts work performance, $83.5 \%$ of the participants indicated a 5 or higher $(\mathrm{M}=5.23, \mathrm{Mdn}=5.0, \mathrm{SD}=1.472)$. Similarly, for how working impacts their performance as a mother, $85.2 \%$ of the women indicated a 5 or higher $(\mathrm{M}=5.46, \mathrm{Mdn}=6.0, \mathrm{SD}=1.53)$. When asked about the importance of being an employee and a mother, the sample highly valued both roles. The items ranged from 1 to 7 with ( $1=$ totally not important and $7=$ totally important). A total of $80.9 \%$ indicated a 5 or higher $(\mathrm{M}=5.44, \mathrm{Mdn}=6.0, \mathrm{SD}=1.47)$ and $94.5 \%$ reported that being a mother was "totally important" to them $(\mathrm{M}=6.84, \mathrm{Mdn}=7.0, \mathrm{SD}=0.87)$. In addition, bivariate correlational tests were run to measure relations among each of the major variables.

\section{Major analyses}

Structural equation modeling (SEM) was used to analyze the hypotheses using EQS [42]. The fully mediated model hypothesis was tested by evaluating the measurement and structural models.

Hypothesis 1 (fully mediated model comparison): The final measurement model fit (The LM test recommended four additional parameter estimations) indices were $\chi^{2}(502)=1328.220, \mathrm{p}<0.001$. The fit statistics were acceptable, AIC $=324.220, \mathrm{CFI}=0.989, \mathrm{GFI}=0.902$, $\mathrm{NNFI}=0.988, \quad \mathrm{SRMR}=0.058, \quad \mathrm{RMSEA}=0.049 \quad(95 \% \quad \mathrm{CI}=46,0.053)$ $\mathrm{p}<0.001$. An evaluation of the hypothesized structural model (fully mediated) revealed a good fit of the model to the data: $\chi^{2}(498)=1321.566$, $\mathrm{p}<0.001 ; \quad \mathrm{AIC}=325.566, \quad \mathrm{CFI}=0.989, \quad \mathrm{GFI}=0.896, \quad \mathrm{NNFI}=0.988$, $\mathrm{SRMR}=0.058, \mathrm{RMSEA}=0.049,(95 \% \mathrm{CI}=0.046,0.053)$. Thus, based on the fit indices alone, the hypothesized fully mediated model indicated a very good fit, thus supporting $\mathrm{H}_{1}$.

Partial mediated and non-mediated model comparisons: To retain a fully mediated model, the model must be compared to competing models in addition to overall goodness of fit $[43,44]$ specifically the partial mediated and non-mediating models for the current study. The partial mediated model demonstrated adequate fit; $\chi^{2}(492)=1303.865, \mathrm{p}<0.001, \mathrm{AIC}=319.865$, RMSEA $=0.049,95 \%$ $\mathrm{CI}=0.046,0.053 \quad(\mathrm{p}<0.001), \mathrm{CFI}=0.989, \mathrm{GFI}=0.897, \mathrm{NNFI}=0.988$. The non-mediated model fit statistics demonstrated adequate fit as well; $\chi^{2}(496)=1303.867, \mathrm{p}<0.001, \mathrm{AIC}=311.867, \mathrm{RMSEA}=0.049,95 \%$ $\mathrm{CI}=0.046,0.052(\mathrm{p}<0.001), \mathrm{GFI}=0.897, \mathrm{NNFI}=0.988 ; \mathrm{CFI}=0.989$.

A nested $\chi 2$ test determined which model to retain based on the differences chi squared values, best fit indices, and a review of the AIC. The initial comparison was between the fully mediated and partialmediated model, indicating that the fully mediated model had trivial but significantly worse fit than the partial mediated model, $\Delta \chi^{2}(6)=17.701$, $\mathrm{p}<0.008 ; \Delta$ AIC $=5.701, \eta^{2}=0.017$. The next comparison was between the partial mediated and non-mediated models. The results revealed that there was no significant difference between the partial mediated and non-mediated models, thus as recommended by the literature [45] the parsimonious model would be retained (i.e., the non-mediating model), $\Delta \chi^{2}(4)=0.002, p>0.05, \eta^{2}<0.0001$. The non-mediating model was compared to the fully mediating model (highest level of parsimony), indicating that the non-mediating model is significantly better than the fully mediating model but only a trivial difference in regard to effect size was observed, $\Delta \chi^{2}(2)=17.699, p<0.003 ; \Delta$ AIC $=13.699, \eta^{2}=0.002$ ); $\eta^{2}=0.000$. In conclusion, the fully mediated model was retained as the difference of effects in the models were trivial at most, supporting the model that best fits the theory of Work-Family Conflict.

Finally, to test the threat of temporal precedence, a fully mediated reversal model was tested and compared via a hierarchical $\chi^{2}$ difference test. That is, Work Satisfaction and Family Satisfaction were set up as antecedents of TBWFC and TBFWC and the outcome variables were Work Hours, Work Demands, and Family Demands. Results of the comparison revealed that both the hypothesized fully mediating model, $\Delta \chi^{2}(2)=199.022, p<0.001 ;{ }_{\text {adj }} \eta^{2}=0.292$, demonstrated significantly better fit than the reversal model. Thus, the direction of the hypothesized relations among the constructs were supported.

Hypotheses A-J (specific pathways): The hypothesized pathways were based on the fully mediated model. Pathway $\mathrm{H}_{\mathrm{A}}$ from work hours to TBWFC was significant in the predicted positive direction $(\beta=0.213$, $\mathrm{p}<0.01$ ); work hours was not significantly related to TBFWC, rejecting $\mathrm{H}_{\mathrm{B}}$. Work demands was significantly and positively related to both TBWFC $\left(\mathrm{H}_{\mathrm{c}} ;(\beta=0.298, \mathrm{p}<0.01)\right.$, as well as significantly and positively related to TBFWC $\left(\mathrm{H}_{\mathrm{D}} ; \beta=0.169, \mathrm{p}<0.01\right)$. Similarly, Family Demands was significantly positively related to both TBWFC $\left(\mathrm{H}_{\mathrm{E}} ; \beta=0.149\right.$, $\mathrm{p}<0.01)$, and TBFWC $\left(\mathrm{H}_{\mathrm{F}} ; \beta=0.451, \mathrm{p}<0.01\right)$. Thus, the only nonsignificant antecedent-conflict relation was Work Hours to TBFWC. TBWFC was significantly and negatively related to Work Satisfaction $\left(\mathrm{H}_{G} ; \quad(\beta=-0.372, \mathrm{p}<0.01)\right.$ but not significantly related to TBFWC (rejecting $\mathrm{H}_{\mathrm{H}}$ ). Likewise, TBFWC was not significantly related to Work 
Satisfaction (rejecting $\mathrm{H}_{\mathrm{I}}$ ), but TBFWC was significantly and negatively related to Family Satisfaction (supporting $\mathrm{H}_{\mathrm{r}} \beta=-0.160, \mathrm{p}<0.01$ ). In conclusion, the origin of work conflict significantly predicted work satisfaction whereas the origin of family conflict significantly predicted solely family satisfaction, rejecting the hypothesized cross-domain pathways of TBWFC to family satisfaction and TBFWC to work satisfaction

\section{Discussion}

\section{Integration of findings}

Current research on work-family related constructs typically involves the isolation of work related antecedents solely predicting work-related outcomes. Researchers have acknowledged the lack of including family factors when considering work related constructs. The idea of "cross-domain relations" defined as, "the extent to which factors in the work domain are related to satisfaction with family life and the extent to which factors in the family domain are related to satisfaction with work life" is an important component to the current study. There were significant cross domain relations as the higher the demands at work and home led to higher WFC and FWC regardless of the domain. On the contrary, same domain relations of higher WFC predicting lower work satisfaction and higher FWC predicting lower family satisfaction were also evidenced. Ultimately, the hypothesized fully mediated model was retained based on good fit and theoretical support. Working mothers with greater work and family demands and higher work hours tended to have higher work-family conflict, and this in turn was related to lower work satisfaction. Working mothers with greater work and family demands experienced significantly higher FWC and subsequently had lower family satisfaction. Nevertheless, these findings should be considered in the context of not only the strengths of the current study, but also important limitations.

\section{Major findings}

The hypothesized fully mediated model was found to best capture the constructs in the simplest manner, supporting the theory of WFC and mediating models in the literature [46]. The fully mediated model not only had good fit indices, but also best encapsulated the theoretical relations of WFC. The fully mediated model suggests that TBWFC and TBFWC fully explain the relations between work hours, demands, and satisfaction, beyond the direct relations between each of the predictors and work and family satisfaction. In addition, it does not matter what type of demand the mother is experiencing as either form of demand will influence both same domain (higher work demands increasing TBWFC) and cross-domain conflict (family demands influencing TBWFC), a finding not heretofore established. Ultimately, the crossdomain relations matter most when looking at antecedents of conflict but that it differs, as same domain relations are most important among conflict and satisfaction.

A major implication for theory is to further promote comprehensive theoretical models that include both work and family variables, particularly mediated models. Being that work antecedents can predict family outcomes, and based on the theory of work-family spillover, an empirical test of the cross-domain relations is essential for promoting a better understanding of work-family research. Thus, the more recent findings of Greenhau and Powell [47] may best capture the shift in understanding relations between work and family as origins of work and family spillover, not as easily separated.

In conclusion, the findings provide further insight into the working mother's experience above and beyond previous research. The specific mediators of TBWFC/TBFWC further support the need to evaluate how specific forms of conflict explain varying relations. In fact, the present study is suggesting that mediated models are most appropriate when attempting to understand the full experience of what causes conflict and subsequently, what conflict then causes. Furthermore, if a researcher were to understand satisfaction, the most appropriate predictors for the women studied here would be conflict. The recommendation in previous research to examine specific dimensions of work-family conflict as mediators was supported in the current study being that these two specific types of conflict related to time (i.e., time-based WFC/FWC) as mediating variables did best captured the relations.

\section{Limitations}

There are notable limitations to this study that need to be addressed. Retaining the fully mediated model is not without alternative considerations. Both competing models had adequate fit, however, it is essential to examine the statistical findings in conjunction with extant theory to determine the model to retain. In this case, the fully mediated model was more parsimonious and was more consistent with the existing literature than the non-mediated model.

The norm comparison tests demonstrated lower scores on the perceived work demand sub-scale (PWD), lower family satisfaction scores (FSS), higher family to work conflict (TBFWC) and higher job satisfaction (aJIG). These findings have several implications, especially as both measures of the dependent variables demonstrated significantly different norm comparisons. This sample was biased in regard to the high percentage of Caucasian, middle to upper-middle socioeconomic status mothers, who are not representative of the population of working mothers in the U.S. The sample consisted of only $14.6 \%$ identifying as working part-time, with the total sample working on average 38.36 hours per week and an average total income of \$131.994.88. Data collection was mostly through social media, requiring the participant to have access to a computer.

It is essential to recognize and acknowledge that fathers' experiences should not be disregarded. Recent literature has shown that father's experience WFC at the same level, if not higher in some cases, than mothers. Consequently, this study is limited to inferences based on working mothers, however, future research should measure working fathers experiences as well.

\section{Strengths}

A fundamental strength of the study was the inclusion of specific mediating variables (TBWFC/TBFWC) to further expand the workfamily literature. In fact, as suggested by Allen, mediating models were necessary to advance the theory of WFC. Beyond WFC, the incorporation of work satisfaction and family satisfaction, and work demands/family demands simultaneously, was also an advantage of the study. In addition, previous researchers suggested the need to examine pathways between WFC and family satisfaction as well as FWC and job satisfaction rather than solely domain specific hypothesized relationships e.g., WFC with job satisfaction. These cross-domain hypothesized relations demonstrated to be significant, providing further support for inclusion of cross-domain relations in WFC literature.

The majority of research on work hours has used work hours as the predictor and satisfaction as the criterion variable. WFC may predict the number of hours that a woman works and the demands that she perceives. The incorporation of the reversal model sought to determine the appropriate direction of the variables. Results demonstrated that 
the reversal model had poor fit, strengthening the evidence of temporal precedence.

\section{Future research}

The current study's findings illustrate the need for replication, meriting further testing of TBWFC/TBFWC as mediators. Being that this study was limited, it is essential to capture two other samples: single working mothers and working fathers. These populations clearly experience conflict both at home and at work as well as have alternate stressors that need to be considered. Furthermore, the current sample of working mothers is skewed in regard to race and SES. In return, future research should focus on the specific experiences of working mothers who represent more varying levels of SES and diverse racial ethnic backgrounds.

Theoretical evolvement is required for several of the constructs used in the current study. The construct and antecedents of work demands and family demands are broadly defined in the literature. Thus, it is suggested that a focus of future theoretical work and research includes defining work and family demands in a comprehensive manner for better inferences to be made.

In relation to WFC/FWC, the current study tested the specific mediators of time-based WFC and FWC. Future research should continue to test specific dimensions of conflict (i.e., time, role, strain) and how they differ, as well as compare the specific mediators to the broader mediators of WFC/FWC. Finally, and most notably, being that a mediating model was retained; future tests of the WFC theoretical model should continue to empirically evaluate mediated models. Additional antecedents and outcomes of conflict should purposefully be incorporated into the model.

\section{Compliance with ethical standards}

Funding: This study was not funded or supported by any grants.

Ethical approval: All procedures performed in studies involving human participants were in accordance with the ethical standards of the institutional and/or national research committee and with the 1964 Helsinki declaration and its later amendments or comparable ethical standards.

Per APA ethical guidelines, the research was conducted following the approval of the Institutional Review Board. Informed consent was obtained from all individual participants included in the study.

\section{References}

1. Noor NM (2004) Work-family conflict, work- and family-role salience, and women's well-being. The Journal of Social Psychology 144: 389-405.

2. Bianchi SM, Milkie MA (2010) Work and family research in the first decade of the $21^{\text {st }}$ century. Journal of Marriage and Family 72: 705-725.

3. Poduval J, Poduval M (2009) Working mothers: How much working, how much mothers, and where is the womanhood? Mens Sana Monogrs 7: 63-79.

4. Cohn D, Livingston G, Wang W (2014) Comparing stay-at-home and working mothers Pew Resaerch Social and Demographic Trends.

5. Greenhaus JH, Beutell NJ (1985) Sources of conflict between work and family roles. Academy of Management Review 10: 76-88.

6. Shockley KM, Singla N (2011) Reconsidering work-family interactions and satisfaction: A meta-analysis. J Manage 37: 861-886.

7. Barnett RC (1998) Toward a review and reconceptualization of the work and family literature. Genetic, Social, and General Psychology Monographs 124: 125-182.

8. Nomaguchi KM, Milkie MA, Bianchi SM (2005) Time strains and psychological well-being. Journal of Family Issues 26: 756-792.
9. Higgins C, Duxbury L, Johnson KL (2000) Part-time work for women: Does it really help balance work and family? Human Resources Management 39 : 17-32.

10. Byron K (2005) A meta-analytic review of work-family conflict and its antecedents. Journal of Vocational Behavior 67: 169-198.

11. Buehler C, O Brien M, Walls JK (2011) Mothers part-time employment: Child, parent, and family outcomes. Journal of Family Theory \& Review 3: 256-272.

12. Allen TD, Herst DEL, Bruck CS, Sutton M (2000) Consequences associated with work to-family conflict: A review and agenda for future research. Journal of Occupational Health Psychology 5: 278-308.

13. Ford MT, Heinen BA, Langkamer KL (2007) Work and family satisfaction and conflict: A meta-analysis of cross-domain relations. Journal of Applied Psychology 92: 57-80.

14. Frone MR, Russell M, Cooper ML (1992) Antecedents and outcomes of workfamily conflict: Testing a model of the work-family interface. Journal of Applied Psychology 77: 65-78.

15. Reynolds J, Aletraris L (2007) Work-family conflict, children, and hour mismatches in Australia. Journal of Family Issues 28: 749-772.

16. Goode WJ (1960) A theory of role strain. American Sociological Review 25 483-496.

17. Sieber SD (1974) Toward a theory of role accumulation. American Sociological Review 39: 567-578.

18. Marks S (1977) Multiple roles and role strain: Some notes on human energy, time, and commitment. American Sociological Review 42: 921-936.

19. Marshall NL, Barnett RC (1993) Work-family strains and gains among two earner couples. Journal of Community Psychology 21: 64-78.

20. Weiner IB, Freedheim DK, Schinka JA, Nezu CM, Geller PA (2003) Handbook of psychology: Health psychology. London UK: John Wiley and Sons.

21. Brauchli R, Bauer GF, Hammig O (2011) Relationship between time-based work-life conflict and burnout: A cross-sectional study among employees in four large Swissenterprises. Swiss Journal of Psychology 70: 165-173.

22. Boyar S, Maertz G, Mosle D, Carr J (2008) Work-family demand on work-family conflict. Journal of Managerial Psychology 23: 215-235.

23. Brough P, O'Driscoll MP, Kalliath, TJ (2005) The ability of 'family friendly' organizational resources to predict work-family conflict and job and family satisfaction. Stress and Health 21: 223-234.

24. Korabik K, Lero DS, Whithead DL (2008) Handbook of work-family integration Research, theory and best practices (1stedn), San Diego CA: Elsevier.

25. Georgellis $Y$, Lange T, Tabvuma V (2012) The impact of life events on job satisfaction. Journal of Vocational Behavior 80: 464-473.

26. Michel JS, Mitchelson JK, Kotrba LM, LeBreton JM, Baltes BB (2009) A comparative test of work-family conflict models and critical examination of work-family linkages. Journal of Vocational Behavior.

27. Kossek E, Ozeki E, Cynthia (1998) Work-family conflict, policies, and the joblife satisfaction relationship: A review and directions for organizational behavior human resources research. Journal of Applied Psychology 83: 139-149.

28. Carlson DS, Kacmar MK, Wayne JH, Grzywacz JG (2006) Measuring the positive side of the work-family interface: Development and validation of a work-family enrichment scale. Journal of Vocational Behavior 68: 131-164.

29. Zabriske RB, McCormick BP (2003) Parent and child perspectives of family leisure involvement and satisfaction with family life. Journal of Leisure Research 35: 163-189.

30. Olson DH, Gorall DM (2003) Circumplex model of marital and family systems In F. Walsh (Ed.), Normal family processes New York, NY: Guilford.

31. Tomlinson $\mathrm{J}$ (2008) Causes and consequences of the divergent working-time patterns of employed mothers in the UK and the US: Developing a comparative analysis. Gender Issues 25: 4-25.

32. Madsen SR, Hammond SC (2006) The complexification of work-family conflic theory:A critical analysis Journal of Critical Postmodern Organization Science 4: 151-179.

33. Bruck CS, Allen TD, Spencer PE (2002) The relation between work family 
Citation: Berger L (2018) Working Mothers Satisfaction: The Influence of Time Demands and Time-Based Conflict. J Ment Disord Treat 4: 158. doi:10.4172/2471-271X.1000158

Page 8 of 8

conflict and job satisfaction:A finer-grained analysis. Journal of Vocational Behavior 60: 336-353.

34. Geurts SAE, Kompier MAJ, Roxburgh S, Houtman IL (2003) Does workhome interference mediate the relationship between workload and well-being? Journal of Vocational Behavior 63: 532-559.

35. Hughes EL, Parkes KR (2007) Work hours and well-being: The roles of work time control and work-family interference. Work and Stress 21: 264-278.

36. Van Rijswijk K, Bekker MHJ, Rutte CG, Croon MA (2004) The relationships among part-time work, work-family interference and well-being. Journal of Occupational Health Psychology 9: 286-295.

37. MacCallum RC, Roznowski M, Necowitz LB (1992) Model modifications in covariance structure analysis: The problem of capitalization on chance. Psychological Bulletin 111: 490-504

38. Carlson DS, Kacmar MK, Wayne JH, Grzywacz JG (2006) Measuring the positive side of the work-family interface: Development and validation of a work-family enrichment scale. Journal of Vocational Behavior, 68: 131-164.

39. Lapierre LM, Spector PE, Allen TD, Poelmans S, Cooper CL (2008) Familysupportive organization perceptions, multiple dimensions of work-family conflict, and employee satisfaction: A test of model across five samples. Journal of Vocational Behavior 73: 92-106.
40. Ironson GH, Brannick MT, Smith PC, Gibson WM, Paul KB (1989) Construction of global job in general scale. Journal of Applied Psychology 74: 193-200.

41. Russell SS, Spitzmuller C, Lin LF, Stanton JM, Smith PC (2004) Shorter can also be better: The abridged job in general scale. Educ Psychol Meas 64: 878-893.

42. Bentler PM and Wu EJ (1995) EQS for Windows User's Guide. Encino CA

43. Byrne BM (2006) Structural equation modeling with EQS: Basic concepts, applications, and programming. Mahwah.

44. Kline RB (2010) Principles and practice of structural equation modeling. New York: Guilford Press.

45. Bentler PM, Satorra A (2010) Testing model nesting and equivalence Psychological Methods 15: 111-123.

46. Geurts SAE, Kompier MAJ, Roxburgh S, Houtman IL (2003) Does workhome interference mediate the relationship between workload and well-being? Journal of Vocational Behavior 63: 532-559.

47. Greenhaus JH, Powell GN (2012) The family-relatedness of work decisions: A framework and agenda for theory and research. Journal of Vocational Behavior 80: 246-255. 